\title{
Longevity of Middle East Respiratory Syndrome Coronavirus Antibody Responses in Humans, Saudi Arabia
}

\author{
Abeer N. Alshukairi, ${ }^{1}$ Jincun Zhao, ${ }^{1}$ Maha A. Al-Mozaini, Yanqun Wang, Ashraf Dada, Salim A. Baharoon, \\ Sara Alfaraj, Waleed A. Ahmed, Mushira A. Enani, Fatehi E. Elzein, Nazik Eltayeb, Laila Layqah, \\ Aiman El-Saed, Husam A. Bahaudden, Abdul Haseeb, Sherif A. El-Kafrawy, Ahmed M. Hassan, \\ Najlaa A. Siddiq, Ibtihaj Alsharif, Isamel Qushmaq, Esam I. Azhar, ${ }^{2}$ Stanley Perlman, ${ }^{2}$ Ziad A. Memish ${ }^{2}$
}

Understanding the immune response to Middle East respiratory syndrome coronavirus (MERS-CoV) is crucial for disease prevention and vaccine development. We studied the antibody responses in 48 human MERS-CoV infection survivors who had variable disease severity in Saudi Arabia. MERS-CoV-specific neutralizing antibodies were detected for 6 years postinfection.

$\mathrm{T}$ hree novel human coronaviruses have caused dif1 ferent worldwide outbreaks that had variable disease severity and geographic distribution: severe acute respiratory syndrome coronavirus (SARS-CoV) during 2003; Middle East respiratory syndrome (MERS) coronavirus (MERS-CoV) during 2012; and severe acute respiratory syndrome coronavirus 2 (SARS-CoV-2), which caused coronavirus disease starting in 2019 (1). Understanding the immune response to coronavi-

Author affiliations: King Faisal Specialist Hospital and Research Center, Jeddah, Saudi Arabia (A.N. Alshukairi, A. Dada,

N.A. Siddiq, I. Qushmaq); First Affiliated Hospital of Guangzhou Medical University, Guangzhou, China (J. Zhao, Y. Wang); King Faisal Specialist Hospital and Research Center, Riyadh, Saudi Arabia (M.A. Al-Moziani, I. Alsharif); King Abdulaziz Medical City, Riyadh (S.A. Baharoon, A. El-Saed); Prince Mohammed Bin Abdulaziz Hospital, Riyadh (S. Alfaraj); Security Forces Hospital, Makkah, Saudi Arabia (W.A. Ahmed); King Fahad Medical City, Riyadh (M.A. Enani); Prince Sultan Military Medical City, Riyadh (F.E. Elzein, N. Eltayeb); King Abdullah International Medical Research Center, Riyadh (L. Layqah); King Saud bin Abdulaziz University for Health Sciences, Jeddah (H.A. Bahaudden); Umm Al Qura University, Makkah, Saudi Arabia (A. Haseeb); King Abdulaziz University, Jeddah (S.A. El-Kafrawy, A.M. Hassan); King Fahd Medical Research Center, Jeddah (E.F. Azhar); University of lowa, lowa City, lowa, USA (S. Perlman); King Saud Medical City, Riyadh (Z.A. Memish); Al-Faisal University, Riyadh (Z.A. Memish)

DOI: https://doi.org/10.3201/eid2705.204056 rus infections is crucial for vaccine development and disease prevention (2). Recurrent MERS-CoV infection has not been described in humans. However, longitudinal studies in seropositive camels detected recurrent infections and intermittent shedding of RNA (3).

A limited number of studies have evaluated the longevity of MERS antibody responses. Payne et al. described persistence of MERS-CoV neutralizing antibodies for $\geq 34$ months postinfection in $6(86 \%)$ of 7 survivors (4). Choe et al. showed that patients who had severe disease had robust MERS-CoV neutralizing antibody titers for 1 year, and patients who had mild disease had waning antibody response over time (5). We assessed antibody responses in 48 MERS survivors who had variable disease severity and duration $\leq 6$ years postinfection.

\section{The Study}

We recruited 48 MERS survivors from 5 hospitals in Jeddah and Riyadh, Saudi Arabia. All participants who agreed to participate provided consent. The study was approved by the institutional research boards of the hospitals involved. All MERS cases were diagnosed on the basis of positive reverse transcription PCR results. Disease severity was divided into 3 categories: mild infection (asymptomatic and upper respiratory tract infection), moderate infection (pneumonia not requiring intubation and ventilation), and severe infection (pneumonia requiring intubation and ventilation in the intensive care unit). Blood samples were collected for serologic testing from survivors in various hospitals at a single time point, except for 1 patient (case-patient 45; Table) who provided samples at 4 and 6 years postinfection. On the basis of date of

\footnotetext{
${ }^{1}$ These authors contributed equally to this article.

${ }^{2}$ These senior authors contributed equally to this article.
} 
diagnosis, MERS-CoV antibody responses were measured 2-6 years postinfection.

An ELISA was performed for 45/49 samples. Microneutralization assays were performed for 43/49 samples in China and 6/49 samples in Saudi Arabia. A total of $43 / 49$ samples were collected 2-5 years postinfection, and 6/49 samples were collected 6 years postinfection. A commercial MERS-CoV
S1ELISA Kit (Euroimmun, https://www.euroimmun.com) was used to measure human IgG titers against the MERS-CoV spike protein as described (6). Samples with an optical density $\geq 1.1$ were considered positive, those $<0.8$ negative, and those $0.8-1.1$ borderline. A MERS-CoV focus reduction neutralization test (modified microneutralization assay) and a MERS-CoV microneutralization test were performed

\begin{tabular}{|c|c|c|c|c|c|c|c|c|c|}
\hline $\begin{array}{l}\text { Patient } \\
\text { ID }\end{array}$ & Age, $y /$ sex & $\begin{array}{l}\text { Time, y between } \\
\text { serologic analysis } \\
\text { and infection }\end{array}$ & Diagnosis & Disease or condition & $\begin{array}{l}\text { Illness } \\
\text { grade }\end{array}$ & $\begin{array}{l}\text { ELISA } \\
\text { result }\end{array}$ & $\begin{array}{c}\text { ELISA } \\
\text { titer }\end{array}$ & $\begin{array}{c}\mathrm{NT} \\
\text { titer }\end{array}$ & $\begin{array}{c}\mathrm{NT} \\
\text { result }\end{array}$ \\
\hline 46 & $34 / \mathrm{F}$ & 6 & AS & Healthy & Mild & - & 0.0 & $<20$ & - \\
\hline 47 & $41 / \mathrm{M}$ & 6 & AS & Healthy & Mild & - & 0.02 & 40 & + \\
\hline 48 & $41 / F$ & 6 & PN & Healthy & Moderate & - & 0.76 & 320 & + \\
\hline 45 & $42 / \mathrm{M}$ & 6 & PN & Healthy & Moderate & - & 0.75 & 80 & + \\
\hline 43 & $56 / \mathrm{M}$ & 6 & SPN & Healthy & Severe & - & 3.0 & 80 & + \\
\hline 44 & $38 / F$ & 6 & SPN & Pregnant, thyroid disease & Severe & + & 2.4 & 80 & + \\
\hline 1 & $52 / F$ & 5 & URTI & HPT, thyroid disease & Mild & - & 0.1 & $<20$ & - \\
\hline 2 & $43 / F$ & 5 & URTI & Healthy & Mild & - & 0.3 & 42 & + \\
\hline 15 & $35 / \mathrm{M}$ & 5 & PN & DM, hyperlipidemia & Moderate & B & 0.8 & 30 & + \\
\hline 33 & $39 / F$ & 4 & URTI & Healthy & Mild & - & 0.7 & 28 & - \\
\hline 7 & $49 / \mathrm{M}$ & 4 & URTI & DM, HPT, BA, IHD, ESRD & Mild & + & 1.5 & 104 & + \\
\hline 34 & $42 / F$ & 4 & URTI & HPT & Mild & + & 1.9 & 144 & + \\
\hline 40 & $28 / F$ & 4 & URTI & Healthy & Mild & NP & NP & 40 & + \\
\hline 41 & $32 / F$ & 4 & AS & Healthy & Mild & NP & NP & 41 & + \\
\hline 31 & 33/M & 4 & URTI & Healthy & Mild & - & 0.5 & 34 & + \\
\hline 32 & $45 / F$ & 4 & URTI & Healthy & Mild & B & 0.9 & 44 & + \\
\hline 3 & 45/M & 4 & PN & Smoker & Moderate & + & 1.1 & 48 & + \\
\hline 5 & $61 / \mathrm{M}$ & 4 & PN & DM, HPT, IHD & Moderate & + & 2.9 & 160 & + \\
\hline 25 & 28/M & 4 & PN & Healthy & Moderate & + & 2.5 & 315 & + \\
\hline 42 & $47 / \mathrm{M}$ & 4 & PN & Healthy & Moderate & NP & NP & 351 & + \\
\hline 45 & $42 / \mathrm{M}$ & 4 & $\mathrm{PN}$ & Healthy & Moderate & NP & NP & 162 & + \\
\hline 29 & $58 / \mathrm{M}$ & 3 & URTI & Healthy & Mild & - & 0.1 & 45 & + \\
\hline 23 & 28/M & 3 & URTI & Healthy & Mild & - & 0.1 & 42 & + \\
\hline 8 & 47/M & 3 & URTI & HPT, hyperlipidemia & Mild & + & 2.5 & 320 & + \\
\hline 18 & $55 / \mathrm{M}$ & 3 & URTI & DM & Mild & + & 3.4 & 648 & + \\
\hline 20 & $34 / \mathrm{M}$ & 3 & URTI & Healthy & Mild & - & 0.6 & 81 & + \\
\hline 26 & 39/M & 3 & URTI & Healthy & Mild & - & 0.6 & 75 & + \\
\hline 35 & 63/M & 3 & URTI & $\mathrm{DM}$ & Mild & + & 2.5 & 501 & + \\
\hline 37 & $61 / \mathrm{M}$ & 3 & URTI & DM, HPT & Mild & + & 1.2 & 81 & + \\
\hline 14 & $32 / F$ & 3 & AS & Healthy & Mild & - & 0.1 & 45 & + \\
\hline 39 & $34 / \mathrm{M}$ & 3 & URTI & Healthy & Mild & + & 1.2 & 31 & + \\
\hline 9 & $36 / F$ & 3 & URTI & Healthy & Mild & - & 0.2 & 32 & + \\
\hline 6 & $74 \mathrm{M}$ & 3 & URTI & DM, lipid & Mild & - & 0.1 & $<20$ & - \\
\hline 10 & $46 / F$ & 3 & AS & Healthy & Mild & - & 0.1 & 20 & - \\
\hline 11 & $47 / F$ & 3 & AS & Grave's disease & Mild & - & 0.1 & 20 & - \\
\hline 12 & $33 / F$ & 3 & AS & Healthy & Mild & - & 0.3 & 20 & - \\
\hline 17 & $54 / F$ & 3 & URTI & HPT, thyroid disease & Mild & + & 4.3 & $<20$ & - \\
\hline 27 & 29/M & 3 & URTI & Healthy & Mild & - & 0.1 & $<20$ & - \\
\hline 30 & $41 / F$ & 3 & URTI & Healthy & Mild & - & 0.2 & $<20$ & - \\
\hline 4 & $41 / \mathrm{M}$ & 3 & $\mathrm{PN}$ & Stroke & Moderate & + & 3.4 & 446 & + \\
\hline 19 & $50 / \mathrm{M}$ & 3 & PN & Healthy & Moderate & + & 3.7 & 315 & + \\
\hline 24 & $54 / \mathrm{M}$ & 3 & PN & DM, HPT, myocarditis & Moderate & + & 2.4 & 398 & + \\
\hline 22 & $57 / \mathrm{M}$ & 3 & PN & Asthma & Moderate & + & 1.9 & 41 & + \\
\hline 16 & $62 \mathrm{~F}$ & 3 & SPN & Asthma, hyperlipidemia & Severe & + & 2.6 & 416 & + \\
\hline 21 & $34 / F$ & 3 & SPN & Healthy & Severe & + & 2.4 & 375 & + \\
\hline 28 & 38/M & 3 & SPN & Healthy & Severe & + & 1.8 & 117 & + \\
\hline 13 & $59 / \mathrm{M}$ & 3 & SPN & Healthy & Severe & - & 0.1 & 20 & - \\
\hline 36 & $64 / \mathrm{M}$ & 2 & URTI & Healthy & Mild & + & 2.5 & 160 & + \\
\hline 38 & $34 / \mathrm{M}$ & 2 & URTI & Healthy & Mild & - & 0.3 & 27 & + \\
\hline
\end{tabular}


in certified Biosafety Level 3 laboratories in Guangzhou, China, and Jeddah, Saudi Arabia, as described $(7,8)$. The cutoff value for a positive neutralization assay result was 1:20 (Appendix, https://wwwnc.cdc. gov/EID/article/27/5/20-4056-App1.pdf). We used reference MERS-CoV isolates (GenBank accession nos. EMC/2012 in Guangzhou and KF958702 in Jeddah).

We presented continuous variables as median and interquartile range (IQR). We used Kruskal-Wallis, Mann-Whitney, Jonckheere-Terpstra, Fisher exact, and Gamma tests to study the differences between variables. All $p$ values were 2-tailed, and $p$ values $<0.05$ were considered significant. We used SPSS Statistics 25.0 (IBM Corp., https:/ / www.ibm.com) for all statistical analyses.

Of 49 specimens, 28 (57.1\%) were collected from MERS convalescent patients at 2-3 years postinfection, $12(24.5 \%)$ at 4 years postinfection, and 9 (18.4\%) at 5-6 years postinfection. Of 49 specimens, $31(63.3 \%)$ were collected from MERS convalescent patients who had mild disease, $12(24.5 \%)$ from those who had moderate disease, and $6(12.2 \%)$ from those who had severe disease (Table). We found that 38/49 specimens had neutralizing antibodies (median [IQR] titer 45 [29-161]). Of these 38 samples, 12 (31\%) were negative by ELISA. Ten of these 12 samples were collected from survivors who had mild illness (Table).

The percentage of samples that had positive neutralizing antibodies was $20 / 28(71.4 \%)$ at $2-3$ years, $11 / 12(91.7 \%)$ at 4 years, and $7 / 9(77.6 \%)$ at $5-6$ years postinfection ( $p=0.405$ for any difference and 0.349 for trend) (Table). The median (IQR) titer of neutralizing antibodies was $45(20-319)$ at 2-3 years, $76(40-162)$ at 4 years, and $42(23-80)$ at 5-6 years postinfection $(p=0.499$ for any difference and 0.755 for trend) (Figure, panel A).

Positive neutralizing antibodies were found in $21(67.7 \%)$ of 31 survivors who had mild disease, 12 $(100.0 \%)$ of 12 survivors who had moderate disease, and $5(83.3 \%)$ of 6 survivors who had severe disease $(\mathrm{p}=$ 0.054 for any difference and $p=0.035$ for trend) (Table). The median (IQR) titer of neutralizing antibodies was 40 (20-81) for survivors who had mild disease, 239 (56-343) for survivors who had moderate disease, and 99 (65385) for survivors who had severe disease, respectively $(p=0.004$ for any difference and $p=0.002$ for trend).

Survivors who had mild, moderate, and severe disease had the following median (IQR) titers for neutralizing antibodies: 37 (20-81), 357 (110-434), and 246 $(44-406)$ at $2-3$ years postinfection $(p=0.109$ for any difference and $p=0.053$ for trend); 41 (34-104) and 162 (104-333) (mild or moderate disease only) at 4 years postinfection ( $\mathrm{p}=0.010)$; and $28(15-42), 80(30-320)$, and $80(80-80)$ at $5-6$ years postinfection $(p=0.130$ for any difference and $\mathrm{p}=0.065$ for trend) (Figure, panel B). We found no major decrease in neutralizing antibody titers over 6 years (Figure, panel A). Survivors who had moderate and severe disease had higher titers than survivors who had mild disease over 6 years (Figure, panel B).

\section{Conclusions}

At 6 years postinfection, we detected antibody responses in $100 \%$ of MERS survivors who had severe
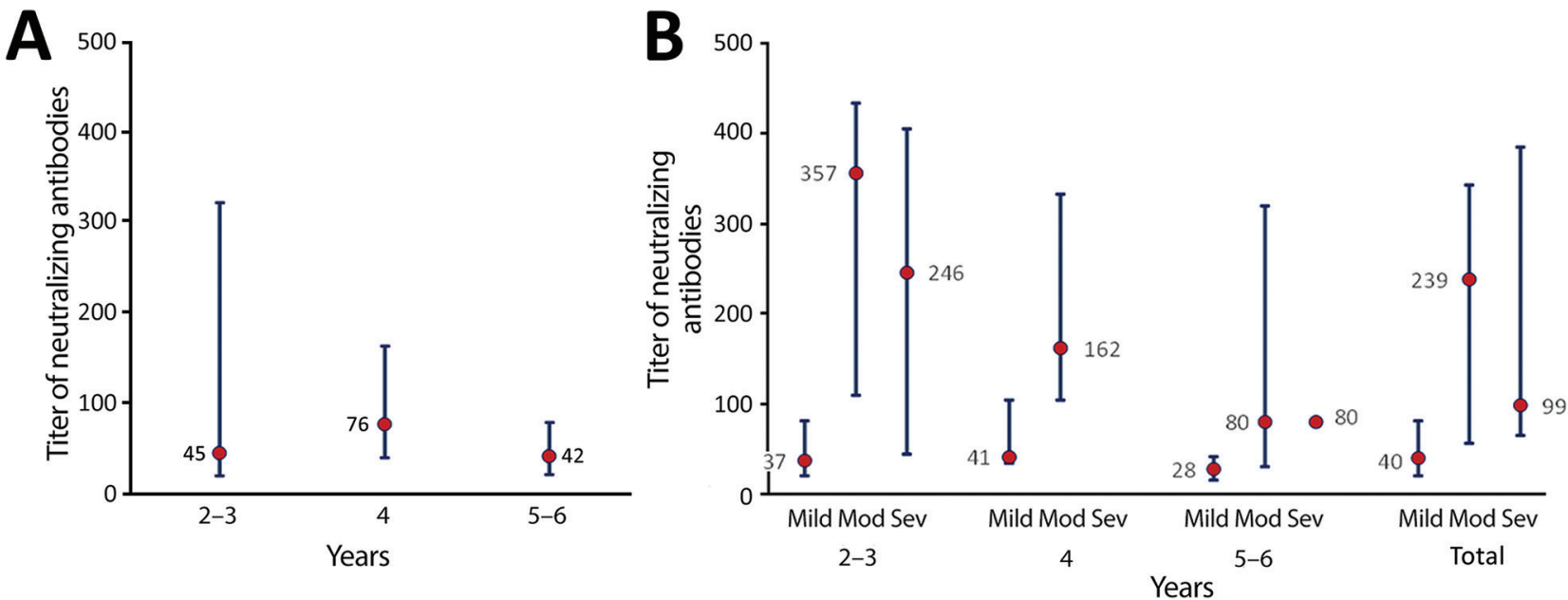

Figure. Neutralization antibody titers in Middle East respiratory syndrome (MERS) convalescent-phase serum samples measured 2--6 years postinfection, Saudi Arabia. Three groups (patients who had mild, moderate, or severe MERS) were enrolled in this study, and serum samples were collected for neutralizing antibody detection (median focus reduction neutralization test titer) at the indicated times after recovery. The cutoff value was 1:20. Median titers of neutralizing antibody (red dots) and interquartile range (blue bars) were measured according to years postinfection (panel A) and disease severity (panel B). There was no major decrease in neutralizing antibodies over 6 years postinfection. Survivors who had moderate and severe disease had higher neutralizing antibody titers then survivors who had mild disease. Mod, moderate; Sev, severe. 
or moderate disease and in $50 \%$ of survivors who had mild disease, demonstrating durability of the MERS$\mathrm{CoV}$-specific antibody response. Because we did not measure MERS-CoV-specific T lymphocyte responses, the number of MERS survivors who had detectable immune responses was probably underestimated. T-cell responses were detected in several MERS survivors who had negative antibody responses at 6 months postinfection (9). The results are consistent with those of previous studies, which the association between disease severity and decrease of antibody response in MERS survivors over time (10). Similar results were described after the SARS epidemic. SARS survivors had persistent antibody responses for 3 years postinfection, and a decrease by 6 years postinfection $(11,12)$. However, a recent study indicated that low levels of SARS-CoV-specific antibody could be detected in some survivors at 12 years postinfection (X. Guo et al., Sun Yat-sen University, pers. comm., 2020 Jan 1).

In this study, we performed ELISA and neutralizing antibody assays for all cases. Although cases of severe disease showed good concordance between the 2 assays, some cases of mild or moderate disease had a negative ELISA result and a positive neutralizing test result. Similar results were observed in camel workers who had asymptomatic MERS-CoV infections, most of whom who had negative ELISA results but detectable neutralizing antibody titers (13). Negative ELISA results might reflect either insensitivity of the assay or high cutoff values established by the manufacturer to minimize the rate of false-positive results. In either instance, these results suggest that negative ELISA results should be read with caution in some settings.

A limitation of our study was the small number of cases of moderate or severe disease and a lack of serial samples for nearly all patients. It will also be useful to determine whether levels of antibody would be protective if MERS-CoV reinfection occurred. In conclusion, we showed that virus-specific neutralizing antibodies are detectable in most MERS survivors for $\geq 6$ years, consistent with durable immunity against the virus.

\section{Acknowledgments}

We thank all the patients for participating in the study and the late Sheikh Ibraheem Ahmed Azhar for providing reagents and supplies.

This study was supported by grants from the National Institutes of Health, USA (PO1 AI060699) and the National Science and Technology Project (81772191).
S.M.F organized data; A.N.A. designed the study, collected data, and wrote the manuscript; S.P. designed the study, analyzed data, and reviewed the manuscript; Z.A.M. investigated study sites and reviewed the manuscript; J.Z., M.A.A., E.I.A., A.D., Y.W., I.A., A.M.H., and S.A.E, performed experiments; S.A.B, S.A., W.AA., M.A.E., F.E.E., N.E.M., L.L., and HAB investigated sites; N.A.S. and I.Q. provided samples; and A.E.S. and A.H. analyzed data.

\section{About the Author}

Dr. Alshukairi is an infectious diseases consultant at the King Faisal Specialist Hospital and Research Center, Jeddah, Saudi Arabia. Her primary research interest is immune responses against human coronaviruses, including MERS-CoV and SARS-CoV-2.

\section{References}

1. Perlman S. Another decade, another coronavirus. N Engl J Med. 2020;382:760-2. https:// doi.org/10.1056/ NEJMe2001126

2. Sariol A, Perlman S. Lessons for COVID-19 immunity from other coronavirus infections. Immunity. 2020;53:248-63. https://doi.org/10.1016/j.immuni.2020.07.005

3. Ali MA, Shehata MM, Gomaa MR, Kandeil A, El-Shesheny R, Kayed AS, et al. Systematic, active surveillance for Middle East respiratory syndrome coronavirus in camels in Egypt. Emerg Microbes Infect. 2017;6:e1. https:/ / doi.org/10.1038/ emi.2016.130

4. Payne DC, Iblan I, Rha B, Alqasrawi S, Haddadin A, Al Nsour M, et al. Persistence of antibodies against Middle East respiratory syndrome coronavirus. Emerg Infect Dis. 2016;22:1824-6. https:// doi.org/10.3201/eid2210.160706

5. Choe PG, Perera RA, Park WB, Song KH, Bang JH, Kim ES, et al. MERS-CoV antibody responses 1 year after symptom onset, South Korea, 2015. Emerg Infect Dis. 2017;23:1079-84. https://doi.org/10.3201/eid2307.170310

6. Drosten C, Meyer B, Müller MA, Corman VM, Al-Masri M, Hossain R, et al. Transmission of MERS-coronavirus in household contacts. N Engl J Med. 2014;371:828-35. https:/ / doi.org/10.1056/NEJMoa1405858

7. Wang Y, Zhang L, Sang L, Ye F, Ruan S, Zhong B, et al. Kinetics of viral load and antibody response in relation to COVID-19 severity. J Clin Invest. 2020;130:5235-44. https:/ / doi.org/10.1172/JCI138759

8. Muthumani K, Falzarano D, Reuschel EL, Tingey C, Flingai S, Villarreal DO, et al. A synthetic consensus anti-spike protein DNA vaccine induces protective immunity against Middle East respiratory syndrome coronavirus in nonhuman primates. Sci Transl Med. 2015;7:301ra132. https://doi.org/10.1126/scitranslmed. aac7462

9. Zhao J, Alshukairi AN, Baharoon SA, Ahmed WA, Bokhari AA, Nehdi AM, et al. Recovery from the Middle East respiratory syndrome is associated with antibody and T-cell responses. Sci Immunol. 2017;2:eaan5393. https://doi.org/10.1126/sciimmunol.aan5393

10. Alshukairi AN, Khalid I, Ahmed WA, Dada AM, Bayumi DT, Malic LS, et al. Antibody response and disease severity in healthcare worker MERS survivors. Emerg Infect Dis. 2016;22:1113. https:/ / doi.org/10.3201/ eid2206.160010 
11. Wu LP, Wang NC, Chang YH, Tian XY, Na DY, Zhang LY, et al. Duration of antibody responses after severe acute respiratory syndrome. Emerg Infect Dis. 2007;13:1562-4. https://doi.org/10.3201/eid1310.070576

12. Tang F, Quan Y, Xin ZT, Wrammert J, Ma MJ, Lv H, et al. Lack of peripheral memory $B$ cell responses in recovered patients with severe acute respiratory syndrome: a six-year follow-up study. J Immunol. 2011;186:7264-8. https://doi.org/10.4049/jimmunol.0903490
13. Alshukairi AN, Zheng J, Zhao J, Nehdi A, Baharoon SA, Layqah L, et al. High prevalence of MERS-CoV infection in camel workers in Saudi Arabia. MBio. 2018;9:e01985-18. https://doi.org/10.1128/mBio.01985-18

Address for correspondence: Abeer N. Alshukairi, Adult Infectious Diseases Section, Department of Medicine, King Faisal Specialist Hospital and Research Center, Jeddah, PO Box 40047, Jeddah 21499, Saudi Arabia; email: abeer.alshukairi@gmail.com

\section{January 2021}

\section{Waterborne Infections}

- Impact of Human Papillomavirus Vaccination, Rwanda and Bhutan

- Nosocomial Coronavirus Disease Outbreak Containment, Hanoi, Vietnam, March-April 2020

- Aspergillosis Complicating Severe Coronavirus Disease

- Rising Ethnic Inequalities in Acute Rheumatic Fever and Rheumatic Heart Disease, New Zealand, 2000-2018

- Differential Yellow Fever Susceptibility in New World Nonhuman Primates, Comparison with Humans, and Implications for Surveillance

- Comparative Omics Analysis of Historic and Recent Isolates of Bordetella pertussis and Effects of Genome Rearrangements on Evolution

- Hospitalization for Invasive Pneumococcal Diseases in Young Children Before Use of 13-Valent Pneumococcal Conjugate

- Human Diversity of Killer Cell Immunoglobulin-Like Receptors and Human Leukocyte Antigen Class I Alleles and Ebola Virus Disease Outcomes

- IgG Seroconversion and Pathophysiology in Severe Acute Respiratory Syndrome Coronavirus 2 Infection

- Hannibal's Ophthalmia-A New Answer to an Ancient Question

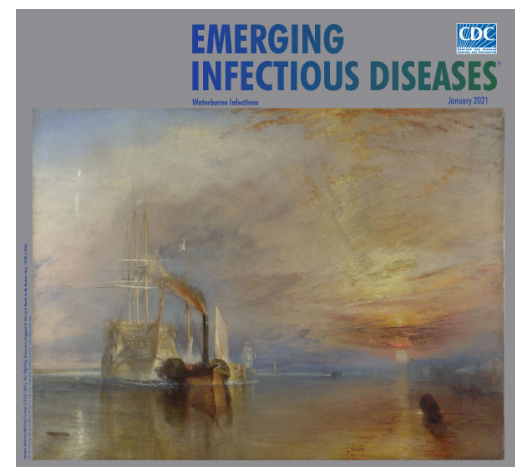

- Susceptibility of Domestic Swine to Experimental Infection with Severe Acute Respiratory Syndrome Coronavirus 2

- Cellular Immunity in COVID-19 Convalescents with PCR-Confirmed Infection but with Undetectable SARS-CoV-2Specific IgG

- Estimating the Force of Infection for Dengue Virus Using Repeated Serosurveys, Ouagadougou, Burkina Faso

- Attribution of Illnesses Transmitted by Food and Water to Comprehensive Transmission Pathways Using Structured Expert Judgment, United States

- Intrafamilial Exposure to SARS-CoV-2 Associated with Cellular Immune Response without Seroconversion, France

- Invasive Fusariosis in Nonneutropenic Patients, Spain, 2000-2015
- Recency-Weighted Statistical Modeling Approach to Attribute Illnesses Caused by 4 Pathogens to Food Sources Using Outbreak Data, United States

- Estimate of Burden and Direct Healthcare Cost of Infectious Waterborne Disease in the United States

- Post-13-Valent Pneumococcal Conjugate Vaccine Dynamics in Young Children of Serotypes Included in Candidate Extended-Spectrum Conjugate Vaccines

- Precise Species Identification by Whole-Genome Sequencing of Enterobacter Bloodstream Infection

- Delineating and Analyzing Locality-Level Determinants of Cholera, Haiti

- Viral Metagenomic Analysis of Cerebrospinal Fluid from Patients with Acute Central Nervous System Infections of Unknown Origin, Vietnam

- Severe Human BocavirusAssociated Pneumonia in Adults at a Referral Hospital, Seoul, South Korea

- Performance of Nucleic Acid Amplification Tests for Detection of Severe Acute Respiratory Syndrome Coronavirus 2 in Prospectively Pooled Specimens

\section{EMERGING} INFECTIOUS DISEASES
To revisit the January 2021 issue, go to: https://wwwnc.cdc.gov/eid/articles/issue/27/1/table-of-contents 